\title{
Better for Everyone? Egalitarian Culture and Social Wellbeing in Europe
}

\author{
Leonie C. Steckermeier ${ }^{1}$ (D) . Jan Delhey ${ }^{1}$ (D)
}

Accepted: 8 October 2018 / Published online: 24 October 2018

(c) The Author(s) 2018, corrected publication 2019

\begin{abstract}
The goal of this study is to explore the relationship between culture and social well-being, focusing on inferiority feelings. While being respected is widely seen as a key ingredient of a good life, inferiority feelings signal a lack of esteem from others. Previous research has mainly looked at income inequality as the key contextual condition for inferiority feelings and other status concerns, often inspired by the income inequality thesis/Spirit Level paradigm (Wilkinson and Pickett 2010). We contribute to this discussion by extending this paradigm into the cultural realm. Our main assumption is that an inegalitarian culture breeds inferiority feelings, whereas an egalitarian culture dampens them and in this sense is "better". Within a multi-level framework we combine information on culture, operationalized as collective values and beliefs, retrieved from the European Value Study for 30 European countries, and survey data on inferiority feelings for over 37,000 individuals from the most recent European Quality of Life Survey (2011-12). Our evidence suggests that widespread self-expression values and social trust (as expressions of an egalitarian culture) are indeed better as they dampen individuals' inferiority feelings while widespread individual blame for poverty (an expression of an inegalitarian culture) heightens them. In further analyses of each income quintile separately, we find evidence that culture mattersfor good or worse-for all income groups, except the poorest quintiles. Our results should prompt scholars of social status and social well-being to pay more attention to the impact of culture.
\end{abstract}

Keywords Social wellbeing $\cdot$ Status anxiety $\cdot$ Values $\cdot$ Beliefs $\cdot$ Inequality $\cdot$ European Quality of Life Survey

The original version of this article was revised due to the retrospective open access order.

Leonie C. Steckermeier and Jan Delhey contributed equally to this article.

Leonie C. Steckermeier

Leonie.Steckermeier@ovgu.de

Jan Delhey

J.Delhey@ovgu.de

1 Institute for Social Sciences, Otto von Guericke University, Zschokkestr. 32, 39104 Magdeburg, Germany 


\section{Introduction}

For a long time, feelings of inferiority have been a concern for scholars interested in the "subjective" and relational consequences of stratification and social inequality (Veblen 1953 [1899]; Sennett and Cobb 1972; Bourdieu 1984 [1979]; Sennett 2003). Recently, there has been a renewed interest in these topics among sociologists, quality-of-life researchers, and epidemiologists. Inferiority feelings are used as an indicator that people are at risk of social exclusion (Böhnke 2004) or have a shortfall in social well-being (Huppert et al. 2009). Most prominently, the Spirit Level theory by Richard Wilkinson and Kate Pickett (2010) has conceptualized inferiority feelings as part of a larger psychological syndrome, status anxiety, which serves as the missing link between inequality and various social problems, including poor health.

A unifying theme in this branch of research is that being esteemed and respected by fellow citizens is a key ingredient of a good life, and hence contributes to a healthy society. Consequently, a feeling of inferiority is corrosive to individual-and collective-wellbeing. Indeed, recent research found inferiority feelings to be associated with poorer mental health (Layte 2012) and self-rated health (Layte and Whelan 2014), re-confirming the large body of evidence on the link between low subjective social status and health problems (e.g. Singh-Manoux et al. 2005; Präg et al. 2016). People who feel inferior are also less happy with their lives (Delhey and Dragolov, 2014; Delhey and Steckermeier 2016), which not only proves true social philosophers (e.g. Skidelsky and Skidelsky 2013), but also Ridgeway's (2014) claim that people do care about their status. Common inferiority feelings are further seen as a social justice problem, as they undermine the very community of equals' modern democracy (Miller 1999) and a strong welfare state (Rosanvallon 2013) are based on.

These harmful consequences for both individuals and societies raise the question of how inferiority feelings are generated, and ideally can be avoided. Whereas the individual-level determinants of status concerns are quite well understood, for the macro-level conditions this does not hold true to the same extent. This article is particularly interested in the conditions of status concerns from a macro-sociological, i.e. contextual, perspective. So far, research has focused on economic inequality as the key contextual condition, mostly confirming its corrosive power (Layte 2012; Layte and Whelan 2014; Delhey and Dragolov 2014; van Deurzen et al. 2015). Yet there is a lack of research on alternative societal forces, including culture, despite the repeated call for such an extension of the hitherto rather narrow research agenda on status concerns (Goldthorpe 2009; Saunders and Evans 2010; Snowdon 2010).

In this paper, we explore culture as a contextual condition of inferiority feelings, specifically examining the role of value climates and belief climates. Our main assumption is that more 'inegalitarian' cultures - those emphasizing hierarchy, achievement and exclusionheighten individuals' inferiority feelings, while more 'egalitarian' cultures - those stressing equality, welfare and inclusiveness-dampen them. Empirically, within a multi-level framework we combine country-level aggregated survey data on values and beliefs for 30 European societies stemming from the European Value Study (EVS) with individual-level survey data on inferiority feelings on more than 37,000 individuals from the third wave of the European Quality of Life Survey (EQLS) for 2011-12. Our evidence suggests that culture is a hitherto underestimated breeding condition for inferiority feelings.

The paper is structured as follows: The next section briefly defines inferiority feelings and discusses micro-level and, specifically, macro-level determinants, including culture 
(Sect. 2). Section 3 familiarizes the reader with those collective values and beliefs that can be expected to have an impact on inferiority feelings. Section 4 introduces our data and measures, Sect. 5 depicts the results, and the concluding Sect. 6 discusses key findings and makes suggestions for further research.

\section{Background: Inferiority Feelings and Their Breeding Conditions}

\subsection{Defining Inferiority Feelings}

We define inferiority feelings as the subjective impression of not counting much in the eyes of others. This includes 'feeling small' when we compare ourselves to others, and a subjectively experienced lack of esteem from others for who we are, what we have, or what we do. Conceptually, inferiority feelings are close cousins of esteem (Ridgeway 2014), reputability (Veblen 1953 [1899]), prestige (Treiman 1977), recognition (Honneth 1995), symbolic capital (Bourdieu 1998), respect (Sennett 2003) and regard (Offer 2006). What unites all these concepts is their social evaluative character, as they are about positive or negative assessments of a person or his/her social roles attributed by fellow citizens. Yet whereas, e.g., prestige is awarded to us by others "objectively" (i.e. independent from our own perception of this attribution), inferiority feelings represent our own subjective interpretation of "the way others feel about us, as expressed in their actions, looks, gestures, words and vocal intonations" (Burkitt 2014: 111). In essence, inferiority feelings are a person's "my feeling" (ibid) about the social worth attributed to him or her by others. Avoiding a sense of inferiority and, even better, gaining respect from fellow citizens is a strong motive for human behavior (Ridgeway 2014), as already Veblen (1953 [1899]) observed.

\subsection{Breeding Conditions: From Economic Inequality to Culture}

The question of who feels inferior and why leads us, first of all, to social stratification, as inferiority feelings are strongly grounded in the relative position an individual holds in the social hierarchy. This is the key message from seminal works on the "hidden injuries of class" (Sennett and Cobb 1972) and class differences in symbolic capital (Bourdieu 1984), as well as from more recent qualitative work on stigmatization experiences of 'McJob workers' (Newman and Ellis 1999). From this perspective, every 'objective' status disadvantage — be it in income, job, education, or any other status dimension — can result in stronger status concerns, while any advantage might work as a protective shield: "If you don't want to feel small, incapable, looked down on or inferior, it is not quite essential to avoid low social status, but the further up the social ladder you are, the easier it becomes to feel a sense of pride, dignity and self-confidence" (Wilkinson and Pickett 2010: 40). Most likely, there are two main channels for how we retrieve information about our social worth: comparing ourselves to others, and how we are treated in everyday-life interactions. As both mechanisms, arguably, are not independent from our relative socio-economic position, a social gradient in inferiority feelings is likely and indeed confirmed for socio-economic status and income (Layte 2012; Layte and Whelan 2014). A broad range of vertical (and horizontal) parameters is discussed by a very recent paper, which further highlights failure on the labor market as taking a toll on people's my-feelings, next to low income (Delhey et al. 2017). 
So far, we have focused on individual-level determinants. Our concern in this study, however, is rather with the societal conditions that work on top of individual positions and thus affect everybody, or almost everybody, in a given society. The so-called inequalitythesis suggests that the surrounding income inequality is the key stressor. E.g., Wilkinson and Pickett argue that "social structures which create relationships based on inequality, inferiority and social exclusion must inflict a great deal of social pain" (2010: 216), as more people are oriented towards dominance. In contrast, "in more egalitarian societies, more people are oriented towards inclusiveness and empathy" (ibid.). As a consequence, people living in low-inequality societies are assumed to show less concern for status issues generally, to engage less in social comparisons, and to experience less status stress. The opposite holds true for those living in high-inequality societies.

To a large extent, the corrosive effect of income inequality is born out in cross-national comparative research which, for reasons of data availability, mostly deals with Europe: In countries with larger income gaps people typically report stronger inferiority feelings (Layte 2012; Layte and Whelan 2014; Delhey and Dragolov 2014), more depression symptoms (van Deurzen et al. 2015), less happiness and life satisfaction (Delhey and Dragolov 2014), and a lower subjective social status (Lindemann and Saar 2014). Yet there is also disconfirming evidence, as a more uneven income distribution leads to less, not more, status-seeking (Paskov et al. 2017), does not push people into social comparisons, and does not weaken psychological coping resources such as self-esteem and optimism (van Deurzen et al. 2015). Finally, the size of the subjective socio-economic-health gradient is not affected by income inequality (Präg et al. 2016).

We are not taking issue with the idea that the income distribution constitutes an important macro-level breeding condition for status concerns. Rather, we are taking issue with the idea that it is the only condition that matters. We assume that the likelihood of experiencing inferiority depends, most generally, on the nature of relationships among groups and individuals prevalent in a given society-in short, a society's dominant "sociocultural style" (Burkitt 2014: 22). The more inegalitarian this style is (i.e. the more hierarchical, competitive, and achievement-focused), the more there is reason for inferiority feelings for everybody, independent of his or her own position in the social hierarchy. But where does such an unhealthy sociocultural style come from? Indeed, one plausible assumption is that it stems from gaping income inequalities, as the "inequality thesis" has it. Yet, an equally plausible assumption is that the sociocultural style is grounded in a society's culture. In the context of the Spirit Level controversy, Saunders and Evans (2010) refer to cultural differences to provide an alternative explanation for why some societies do "better" than others, yet without exploring this issue systematically. With the paper at hand we address this research gap.

\section{Values, Beliefs, and Inferiority Feelings}

\subsection{Culture and Inferiority Feelings: The General Argument}

Our general assertion is that a society's culture colors its sociocultural style of how individuals and groups relate to each other and thus exerts a contextual effect on the social well-being of individuals generally, and on inferiority feelings specifically. To re-phrase the above quote from the Spirit Level: Inegalitarian cultures which create relationships based on inequality, inferiority and social exclusion must inflict a great deal of social pain. They 
are doing so for three main reasons. First, culture either emphasizes or downplays status and related issues such as success and achievement, thereby determining their general salience in a given society. Second, culture provides scripts for social interactions between people of different rank, thereby making encounters for lower-status people more pleasant (if scripts minimize rank) or unpleasant (if rank is underscored). Third, culture provides cues for how to interpret our own achievements and that of others. Ideal-typically distinguishing between inegalitarian and egalitarian cultures, we contest that the former should result in more widespread inferiority feelings, as they implicate a sociocultural style that constantly expose people to social-evaluative stress.

We approach culture via values and beliefs, as is common among social scientists (Lane and Svante 2002). Whereas values are conceptions of what is desirable (Rokeach 1973), beliefs represent convictions about the world, society, and humans (Nolan and Lenski 2004: ch. 3). As we are concerned with culture as a societal characteristic that exerts a contextual effect on-potentially - all members of society, we are primarily interested in climates of values and beliefs, not individual orientations. Following established concepts and measures, we regard individual blame for poverty and a strong social norm to work as exemplary of an inegalitarian cultural climate, and self-expression values and social trust as representative of an egalitarian climate. Note that we do not treat the labels 'egalitarian' and 'inegalitarian' as representing two different qualities, but rather as polar ends of the same quality. Whereas the one end features equality, welfare-orientation and inclusiveness, the other end features hierarchy, achievement-orientation and exclusion. In the following, we carve out what specifically characterizes the values and beliefs we picked as (in)egalitarian and discuss key findings of previous research.

\subsection{Exemplifying (In)egalitarian Cultures}

\subsubsection{Self-Expression Values}

The Inglehart-Welzel approach places societies in a two-dimensional value space (Inglehart and Welzel 2005; Welzel 2010). One axis juxtaposes traditional and secular values (not considered in this paper, as this value dimension is not relevant here), the other axis survival and self-expression values. Whereas survival values emphasize conformity to social norms and the acceptance of hierarchies and unequal opportunities, the latter comprises emancipative orientations which emphasize lifestyle freedom, equality of opportunities, and a concern for one's own well-being and that of others (cf. Welzel 2010). ${ }^{1}$ Thus, a climate of strong self-expression values in a given society should represent an egalitarian culture as defined above.

The relevance to inferiority feelings is obvious: Self-expression values imply a liberation of the individual from social hierarchies, including gender hierarchies, and an emphasis on well-being. Thus, people are encouraged to deal with each other in a more empathetic and inclusive way. Further, different types of people and life-styles are tolerated - and even valued — which should have positive consequences for the psychological

\footnotetext{
1 The labels survival values and self-expression values are used to describe the polar ends of the same value dimension; societies can either fall more towards the survival-end of the value continuum, or towards the self-expression end. Henceforth we will just use the term self-expression values, with societies either scoring low or high on self-expression values (which automatically means that they score high or low on survival values, respectively).
} 
well-being of individuals. Empirically, populations leaning towards self-expression values have been shown to possess a more universal form of altruism (Welzel 2010), more trust in outgroups (Welzel and Delhey 2015), and better health (Inglehart and Oyserman 2004).

\subsubsection{Social Trust}

As a "bet on the future contingent action of others" (Sztompka 1999: 25), trust essentially is the expectation that others act reasonable and are honest and benevolent. Moreover, with a trusting attitude the truster commits himself/herself to the same personal qualities. Trust in general others-i.e. trust in a wide range of people, including outgroups and strangersis widely seen as a resource that works as a social glue and facilitates cooperation (Philips 2006). With a trusting attitude we include others in our "moral community" (Uslaner 2002) and commit ourselves to consider their interests and well-being. Distrust, in contrast, "involves negative, defensive commitment (avoiding, escaping, distancing myself, refusing actions, taking protective measures against those I distrust)" (Sztompka 1999: 26). A culture of general trust, therefore, is egalitarian as it aims at inclusiveness and an empathetic well-being orientation. Empirically, there is a close link between the scale of structural and economic inequality in societies and the amount of trust in populations (Delhey and Newton 2005; Rothstein and Uslaner 2005; Bjornskov 2008); in turn, a trust culture is associated with subjective well-being in terms of happiness and life satisfaction (Bjornskov 2003; Calvo et al. 2012).

\subsubsection{Social Norm to Work}

The norm to work is inegalitarian as it stresses occupational achievement and creates a main hierarchy of social worth between those who work and those who don't. This exclusionary norm works through external and internal sanctions. People who do not work will be stigmatized by others "which create[s] feelings of shame and inferiority" (Stam et al. 2016: 310). At the same time, the internalization of this norm leads to guilt and self-sanctioning mechanisms which consequently harm an individual's well-being (ibid). These harms most likely include a sense of inferiority.

Recent studies employing the social norm to work as an independent variable have focused on life satisfaction. They have shown that the life satisfaction damage caused by exclusion from the labor market is strongly influenced by the social norm to work prevailing in a society, and moreover, that a strong work ethic impairs the well-being of everybody, notwithstanding their individual economic situation (Stavrova et al. 2011: 167f., Eichhorn 2013: 1675). In contrast, Stam et al. (2016: 325f.) found that a strong social norm to work only harms the life satisfaction of a very specific group, namely disabled men. We go with the majority of these studies and expect a broad effect on everybody's sense of inferiority.

\subsubsection{Poverty Beliefs: Individual Blame}

Since their first examination by Feagin (1972), lay explanations of poverty have mostly been characterized by two dimensions. The first dimension distinguishes between individual and social causes, the second between blame and fate (van Oorschot and Halman 2000: 7). We focus on individual blame, as this combination of beliefs about poverty captures most clearly an element of achievement orientation in a given culture. Content-wise, 
individual blame bluntly suggests that the poor are poor because they are lazy and lack will-power-essentially a denial of deservingness. If widespread, this strongly exclusionary type of poverty explanation should create an inegalitarian atmosphere in which people are anxious about their status, as failure is stigmatized.

To the best of our knowledge poverty beliefs have not been utilized as an explanatory variable - neither on an individual nor on an aggregated level—, wherefore we can only build on previous findings concerning the individual and contextual factors which influence poverty attributions themselves. As to the latter, previous research has found that individual blame is less popular in contexts characterized by a higher unemployment rate and economic decline, a low level of (perceived) inequality and poverty, generous social spending, high human development, a weak work ethic, and a strong Catholic tradition (Lepianka 2007, ch. 2; Lepianka et al. 2010: 67f.). Regarding the individual level, within persons individual blame is positively linked to a strong work ethic, economic and political conservatism and support of the merit principle, and negatively related to egalitarianism and post-materialism (Lepianka et al. 2010: 68; Bobbio et al. 2010: 231f.; Lepianka 2007, ch. 2).

In summary, our two hypotheses regarding culture are:

H1: Individuals living in societies with a more egalitarian culture, exemplified as widespread strong self-expression values and social trust, will report less inferiority feelings.

H2: Individuals living in societies with a more inegalitarian culture, exemplified as a strong social norm to work and widespread individual-blame for poverty, will report more inferiority feelings.

In the subsequent analysis, we measure societies' climate of self-expression values, the norm to work, and poverty beliefs with data from the European Values Study and social trust using data from the EQLS. We propose that the influence of an (in)egalitarian culture on people's inferiority feelings is of a contextual nature and does not simply stem from respective individual attitudinal dispositions of people in a society. Unfortunately, due to data limitations, in the subsequent analysis only for social trust it is possible to control for the respective orientation at the individual level, which is the ideal procedure to rule out a composition effect. To mitigate this problem, for the other value/belief climates, we also include respondents' social trust as a proxy for his/her individual orientation towards (in)egalitarianism generally. Empirically, trusters have been found to be more tolerant and respectful towards diverse and disadvantaged groups of people (e.g. Inglehart 2008; Welzel 2010), to be less ethnocentric (Rosar 2004), and to assess the deservingness of immigrants more positively (van Oorschot 2005). Trusters also are more positive about the welfare state and about income redistribution (Soroka et al. 2007; van Oorschot 2006). This evidence suggests that social trust can serve as a proxy for egalitarian orientations generally, and hence be used as a control variable at the individual level.

\section{Does Culture Affect Everybody Equally?}

We additionally explore whether a prevalent culture affects everybody's social well-being equally, or whether it is more corrosive-or healthy, in the case of self-expression values und trust-for some groups than for others. A similar discussion exists for the income 
distribution, inspired by the slogan "equality is better for everyone" (Wilkinson and Pickett 2010). Focusing on the income distribution and income ranks, Layte and Whelan (2014) discuss the possibility that the social gradient of status anxiety is actually steeper in more unequal societies, suggesting that the lower income ranks suffer most from contextual inequality, but they found that "countries with lower levels of income inequality have lower levels of status anxiety at all points on the income rank curve relative to higher inequality countries" (Layte and Whelan 2014: 8). In contrast, van Deurzen et al. (2015) argue that the middle income stratum should actually suffer most from greater inequality, as they expect this stratum to be the most engaged in the rat race of 'keeping up with the Joneses'-more so than both the poor (which tend to avoid status competition) and the rich (which are self-confident due to their superior position). However, van Deurzen et al. finally found only very weak evidence of a stronger corrosive effect for the middle class.

Based on this evidence, we first of all hypothesize that the cultural context also affects everybody's inferiority feelings, as all members of society are exposed to culture-for good (an egalitarian culture) or bad (an inegalitarian culture). Yet we further expect that the lowest income group is penalized most by living in an inegalitarian climate as captured by individual blame for poverty and social norm to work. Our reasoning is that content-wise these two cultural climates address the least successful, be it in terms of income (poverty beliefs) or labor market participation (norm to work), thus putting them under particular social-evaluative stress. These considerations leads to our third and final hypothesis:

H3: The contextual effect of culture on inferiority feelings is felt at all rungs of the income ladder, but inegalitarian cultures specifically increase inferiority feelings among the bottom income quintile.

\section{Data and Methods}

\subsection{Data and Countries}

To test our hypotheses we analyze data from the third round of the European Quality of Life Survey (EQLS 2011-12). Covering 43,636 respondents in 34 European countries the EQLS examines a wide range of objective living conditions and subjective experiences of life. Our research population consists of 37,440 respondents in 30 countries with an annual per capita GDP (in PPP) of more than 15,000 Int'1.\$. As the inequality thesis speaks about rich countries, we apply this threshold in order to separate rich countries from less-affluent societies. This threshold is close to the one suggested by Wilkinson and Pickett (2010) and has been used in previous studies (e.g. Delhey et al. 2017). ${ }^{2}$ To manage the missing data in our dependent variable, inferiority feelings (3.9\%), and in the household income variable $(24.8 \%)$ we performed multiple imputations for missing values using predictive mean matching (PMM) ${ }^{3}$ implemented in the Stata-module MICE. In comparison to other imputation methods, PMM produces values that are closer to real values and follow more

\footnotetext{
2 Proto and Rustichini (2013) showed that the relationship between life-satisfaction and GDP p.c. flattens after a threshold of 15,000 .

${ }^{3}$ Predictive mean matching as implemented in Stata is based on the ideas of Little (1988) and Rubin (1986).
} 
closely the distribution of the original variable (Morris et al., 2014). Using nine predictor variables in our imputation models, we predicted 50 datasets with $\mathrm{k}=20$ donors-Morris et al. (2014) recommend using at least 10 potential donors-and accounted for the nested structure of the data. ${ }^{4}$

\subsection{Measuring Inferiority Feelings}

The EQLS offers us two items to operationalize inferiority feelings which have been used in previous research (Layte 2012; Layte and Whelan 2014; Delhey and Dragolov 2014). Respondents were asked on a five point scale (from 0 to 4 ) whether they agreed or disagreed with the following statements: (1) 'I don't feel the value of what I do is recognized by others' and (2) 'some people look down on me because of my job situation or income'. The items correlate at 0.46 (95\% CI: $0.45-0.47)$. Each respondent's inferiority score is the mean of both items. Inferiority feelings are least prevalent in Denmark (0.66), Germany (0.86), and Iceland (0.91), and most prevalent in the Czech Republic (1.54), Romania (1.60), and Cyprus (1.89).

\subsection{Measuring Values and Beliefs}

\subsubsection{Self-Expression Values}

Following Welzel (2010) we cover three subsets of self-expression values (SEVs), namely: sexual freedom, gender equality, and personal autonomy using data from the European Value Survey 2008. Sexual freedom is measured as the mean of a respondent's attitudes towards the justifiability of abortion and divorce on a ten-point scale. ${ }^{5}$ We operationalize gender equality by the dis-/approval of the following two statements: "When jobs are scarce, men have more right to a job than women" and "If a woman wants to have a child as a single parent, but she doesn't want to have a stable relationship with a man, do you approve or disapprove?". Respondents' emphasis on personal autonomy is operationalized by the selection of qualities a child should learn at home. The qualities "imagination" and "independence" each add one point to the autonomy scale if chosen by the respondent; the qualities "obedience" and "faith" each reduce the scale by one point. All three subsets are then rescaled to range from 0 to 1 and averaged to receive the final score of the self-expression value orientation for each respondent. Aggregated to the country level, self-expression values are most widespread in Iceland, Sweden and Denmark (each $>0.75$ ) and least widespread in Turkey, Malta and Cyprus (each $<0.40)$.

\subsubsection{Social Trust}

We operationalize a culture of trust as the mean value of trust people put in others measured on a ten-point scale from 1 "you can't be too careful in dealing with people" to 10 "most people can be trusted" using data from the EQLS 2011-12. Social trust is weakest

\footnotetext{
4 As a robustness check we re-estimated all contextual effects by income group without missing values and found a substantively identical pattern of results (results not shown, provided upon request).

5 We could not include "justifiability of homosexuality" as this question was not asked in Italy.
} 
in Cyprus (1.84), the Czech Republic (4.01) and Latvia (4.08) and strongest in Sweden (6.41), Denmark (7.01) and Finland (7.17).

\subsubsection{Social Norm to Work}

Following Lepianka et al. (2010), the social norm to work is reflected by the dis-/agreement with five statements included in the European Value Study 2008: (1) "to fully develop your talents, you need to have a job", (2) "it is humiliating to receive money without having to work for it", (3) "people who don't work turn lazy", (4) "work is a duty towards society", (5) "work should always come first, even if it means less spare time". The country scores are the mean values over the five items for all respondents in that country. Scaled from 0 to 1 , the social norm to work is weakest in Iceland and the Netherlands $($ each $<0.55)$ and strongest in Bulgaria, Kosovo, and Turkey (each > 0.75).

\subsubsection{Poverty Beliefs}

We measure the extent of individual blame in a given society as the percentage of people who think the most important reason why people live in need is "because of laziness and lack of willpower" instead of considering them to be "unlucky", victims of "injustice in our society", or a by-product of "modern progress". Again, the European Value Study from 2008 is our data source. The extent of individual blame is lowest in Sweden, Denmark and Iceland $($ each $<15 \%)$ and highest in the Czech Republic and Cyprus (each $>40 \%$ ).

\subsection{Additional Variables}

\subsubsection{Macro-Level Controls}

To comply with the income inequality thesis we include the Gini index of the income distribution as a measurement of income inequality and GDP p.c. as a measure of national economic prosperity. We are using Gini-data for 2011 from Solt's Standardized World Income Inequality Database (Solt 2016) and GDP p.c. at purchasing power parity, divided by 1000 and log-transformed, for 2011 from The World Bank and World Development Indicators (2016).

\subsubsection{Individual-Level Variables}

We derive respondent's household income using the household income in purchasing power parity provided in the EQLS dataset, which we then transform using the OECD's modified equivalence scale in order to adjust for the respective household size.

We use respondent's general social trust as a proxy of their individual attitudes towards inegalitarianism/egalitarianism.

Additionally we control for citizenship (citizen as reference), gender (male as reference), family status (not living with partner as reference), children (not living with children as reference), age and age $^{2}$ (metric), education (six ISCED groups), occupation (never had a job, unskilled manual worker, skilled manual worker, non-manual worker as reference, technician/lower professional, manager/professional, and other), employment status (student, homemaker, retired, unable, currently unemployed, employed as reference, and 
other), home-ownership (living on rent/otherwise rent free as reference), housing problems (no problems as reference), churchgoing (5-point scale from never to daily).

\subsection{Steps of Analyses}

The analysis was conducted in three steps: First, Pearson's correlation coefficients were calculated for all three measures of culture and the country average of inferiority feelings (for country-level descriptive statistics, see Tables 2 and 3 in the Appendix). Second, multi-level linear regression was employed to predict individual inferiority feelings (addressing H1 and H2). Bar the base model, each of the multi-level models comprises the same battery of individual-level variables presented above and-together with GDP p.c. and Gini-iteratively includes one measure of culture at a time. As there naturally is some overlap between the four climates of values and beliefs, considering them simultaneously would result in severe multi-collinearity problems. In these multi-level analyses, three cultural characteristics - trust, self-expression values and individual blame for poverty-contributed significantly to the explanation of variance in inferiority feelings among European societies. Thus, in a third step, the models including these three cultural characteristics were re-estimated after splitting up the sample into five income quintiles per country, to gain insights into group-specific effects of culture (addressing H3).

For all multi-level models the F-test is significant ( $p \leq 0.05)$, the largest FMI is smaller than 0.5 (number of imputations/100), and the average RVI is small. All ICCs are smaller than the ICC of the base model, indicating that the macro-level variables statistically explain some of the variance in inferiority-feelings on country-level. Overall, we have confidence in the fit of our models.

In all multi-level models we control for respondent's social trust as proxy for his/her (in) egalitarian attitude. This approach is used to avoid measuring the composite effect, i.e. the aggregated effect of individual attitudes, and instead to measure the contextual effect of culture on individuals, regardless of their individual (in)egalitarian standpoint.

\section{Results}

\subsection{Inferiority Feelings in Rich European Countries}

The average level of inferiority feelings on a 5-point scale from no (0) to strong (4) inferiority feelings is 1.26 , indicating that Europeans overall are not too afflicted by this sort of status concern (see Fig. 1). Still, when looking at the responses separately, around 20\% of Europeans feel that they are not valued by others, and more than $15 \%$ feel that others look down on them. Another $20 \%$, respectively $12 \%$, are undecided with respect to these statements. Returning to the index, the distribution of inferiority feelings in Europe ranges from a low 0.58 in Denmark to 1.85 in Cyprus. Next to Denmark, also Germany, Iceland and Austria are characterized by weak inferiority feelings with values below 1.0. Next to Cyprus, the strongest feelings of inferiority are reported by people in Romania, Greece, the Czech Republic, Bulgaria, and Poland, each scoring values greater than 1.5 on country level. Whereas the top of the ranking (low inferiority) is comprised of mostly Northern and Central European countries, the bottom (widespread inferiority) mainly consists of Eastern and Southern European countries, as well as the Anglophone countries. 




Fig. 1 Distribution if inferiority feelings in Europe. Note: EQLS 2011-12. Country level means and standard deviations

\subsection{The Relationship Between Culture and Inferiority Feelings}

Figure 2 illustrates the correlations of inferiority feelings (country averages) with the four measures of culture, as well as with the income distribution and national prosperity. We found strong and highly significant correlations between the average inferiority feelings, on the one hand, and the average level of social trust $(-0.72)$, the prevalence of self-expression values $(-0.65)$ and the attribution of poverty to individual laziness $(0.64)$, on the other, as well as a moderate correlation with the norm to work (0.32). All these correlations are in the theoretically expected direction: the more inegalitarian the culture, the more people are plagued by inferiority feelings; the more egalitarian the culture, the less people are plagued. Further, and in line with previous research, both Gini (0.40) and GDP p.c. (- 0.47) correlate significantly with the country-level inferiority feelings, suggesting their relevance as control variables. On average, people feel more inferior in countries with an unequal income distribution, and less inferior in affluent countries. Moreover, Gini and GDP p.c. correlate moderately with the four sets of social values and beliefs-always with the expected sign. A comprehensive correlation matrix on all macro-level measures is available in Table 4 in the Appendix.

\subsection{The Contextual Impact of Culture}

In Table 1 we present the results of four multi-level models estimating the effects of the four cultural measures on individual inferiority feelings, controlled for the above-presented individual-level characteristics to account for population composition (including individual social trust as a proxy for egalitarian/inegalitarian attitudes), as well as for national prosperity and income inequality as structural conditions. As our study focusses on the 

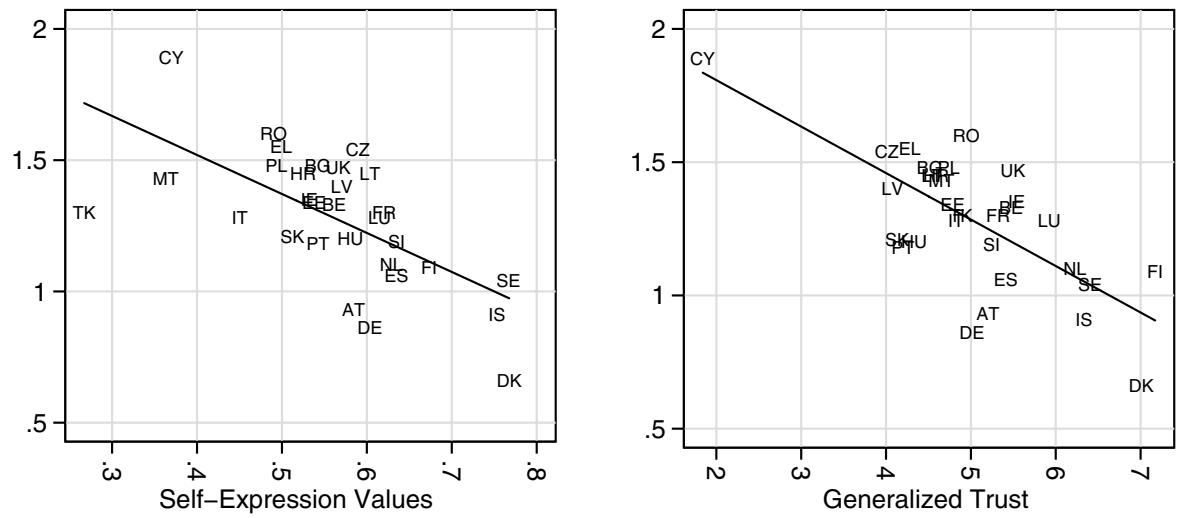

$R=-0.65^{\star \star *}$

$R=-0.72^{\star \star \star}$
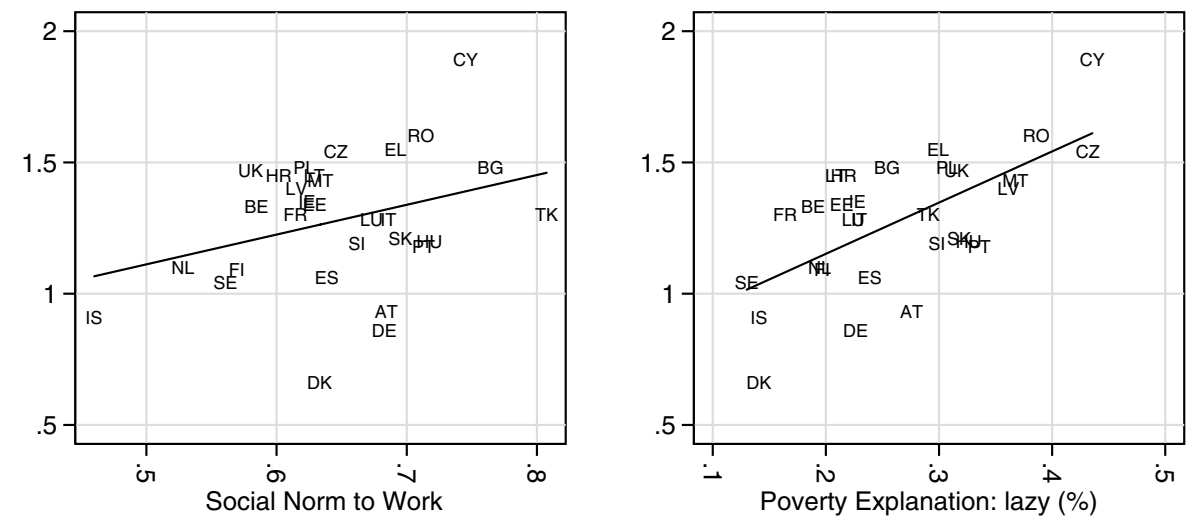

$R=0.32$

$\mathrm{R}=0.64^{\star * *}$
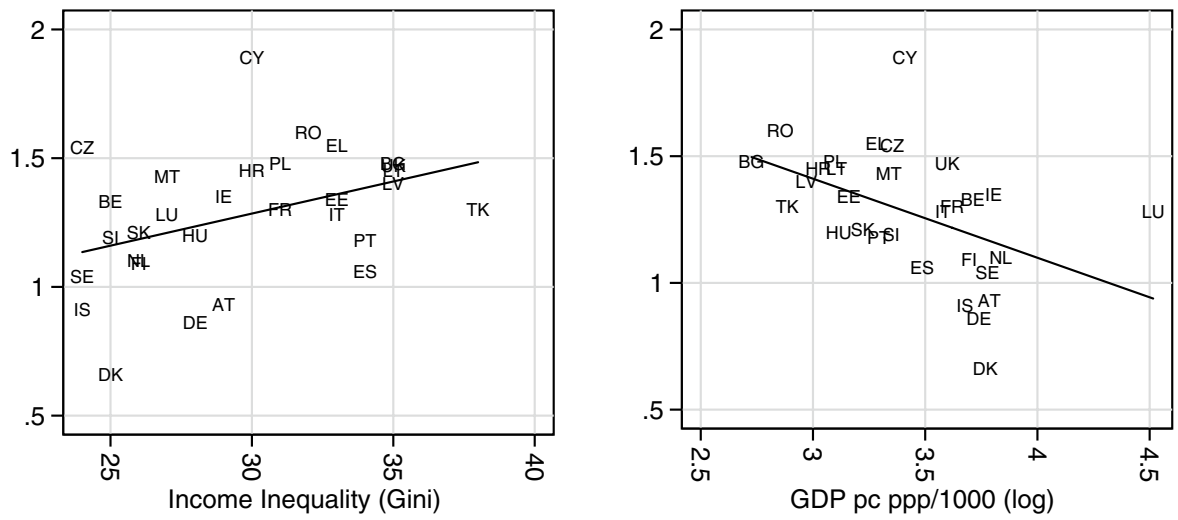

$R=0.40^{*}$

$R=-0.47^{\star * *}$

Fig. 2 Relationship of inferiority feelings with cultural and socio-economic country characteristics. Note: EQLS 2011-12, N = 30, country-level means 


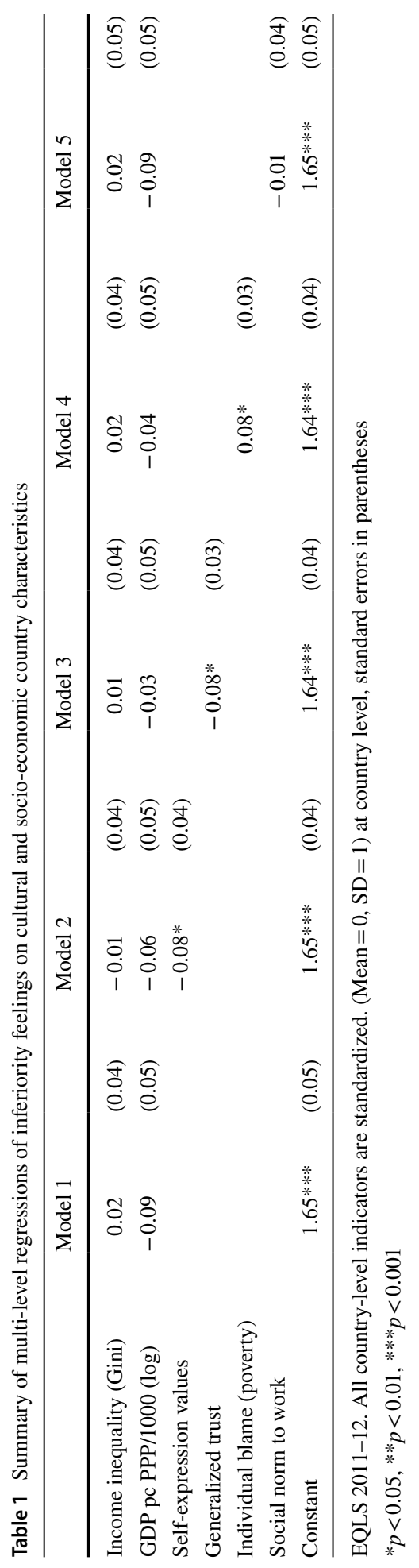


contextual effects, Table 1 just presents the country-level results; the full models including all individual-level effects are shown in Table 5 in the Appendix. A detailed discussion of a similar set of individual-level drivers of inferiority feelings is provided by Delhey et al. (2017). We first estimate an empty model to examine the proportion of variance explained by the country level (Table 5). This yields an intra-class correlation coefficient of 7.2, indicating that individual characteristics are far more important for inferiority feelings than country level factors but nevertheless suggesting multi-level analysis is appropriate.

Estimating one model for each measure of culture individually we find that the prevalence of self-expression values (Model 2), generalized trust (Model 3) and the extent of individual blame for poverty (Model 4) have significant impact on individual-level inferiority feelings (Table 1), over and above the effect of GDP p.c. and Gini. When comparing the least "self-expression oriented" country-Turkey—to the most "self-expression oriented" country-Denmark-the value climate can statistically explain 0.4 points of inferiority feelings. Similarly, a culture of trust dampens inferiority feelings. Between the leastCyprus - and the most trusting society-Finland - the average level of trust explains 0.4 points of inferiority feelings. Regarding poverty beliefs, with every $10 \%$ increase in people who blame the poor for being lazy, inferiority feelings increase by around 0.11 points. In our sample the percentage of individual blame for poverty makes up for about 0.3 points difference in inferiority feelings between the country with the lowest percentage of individual blamers-Sweden - and the country with the highest percentage-Cyprus. In contrast, the social norm to work does not exert a significant influence on inferiority feelings (Model 5). ${ }^{6}$ Moving from culture to structure, the same applies for national prosperity and income inequality; regardless of whether considered together with culture (Models 2-5) or without culture (Model 1), they do not impact the level of inferiority feelings in European societies in a significant fashion. The individual-level proxy for egalitarian values and beliefs, individual social trust, exerts the expected influence: Respondents who put more trust in other people feel less inferior (see Table 5 in the Appendix). The inclusion of trust into all multi-level models strengthens our confidence that the cultural climate effects we demonstrated for self-expression values, trust and poverty beliefs are true contextual effects, not composition effects.

\subsection{Contextual Effects by Income Group}

In the third and last step we repeated the estimation of Models 2, 3 and 4 (see Table 1) after splitting the sample per country into five similar-sized income quintiles: (1) lower, (2) lower middle, (3) middle (4) upper middle and (5) upper income quintile. Figures 3, 4 and 5 summarize in a simplified way the group-specific contextual effects of self-expression values, trust and individual blame for poverty on individual inferiority feelings (the full regression models are provided in the Appendix, Tables 6, 7 and 8).

The amount of surrounding self-expression values tend to work in the same "positive" direction for all income quintiles - all effects are negative, i.e. people feel less inferior (Fig. 3). However, whereas this dampening effect is similarly strong and statistically significant for the

\footnotetext{
${ }^{6}$ We re-ran the models without the gini-coefficient, thus just considering national prosperity and the cultural climate as country-level predictors. The results are almost identical to the findings reported above: While a climate of self-expression values, generalized trust, and individual blame for poverty matters for individual's inferiority feelings (with almost identical coefficients), a strong social norm to work does not matter. The levels of significance remain the same.
} 
Fig. 3 Contextual effects of self-expression values on inferiority feelings in different socio-economic strata. Note: EQLS 2011-12. B-coefficients of standardized self-expression values. Black bars: contextual effect significant at $p<0.05$; grey bars: contextual effect not significant

Fig. 4 Contextual effects of generalized trust on inferiority feelings in different socioeconomic Strata. Note: EQLS 2011-12. B-coefficients of standardized generalized trust. Black bars: contextual effect significant at $p<0.05$; grey bars: contextual effect not significant

Fig. 5 Contextual effects of individual blame on inferiority feelings in different socioeconomic Strata. Note: EQLS 2011-12. B-coefficients of standardized individual blame. Black bars: contextual effect significant at $p<0.05$; grey bars: contextual effect not significant
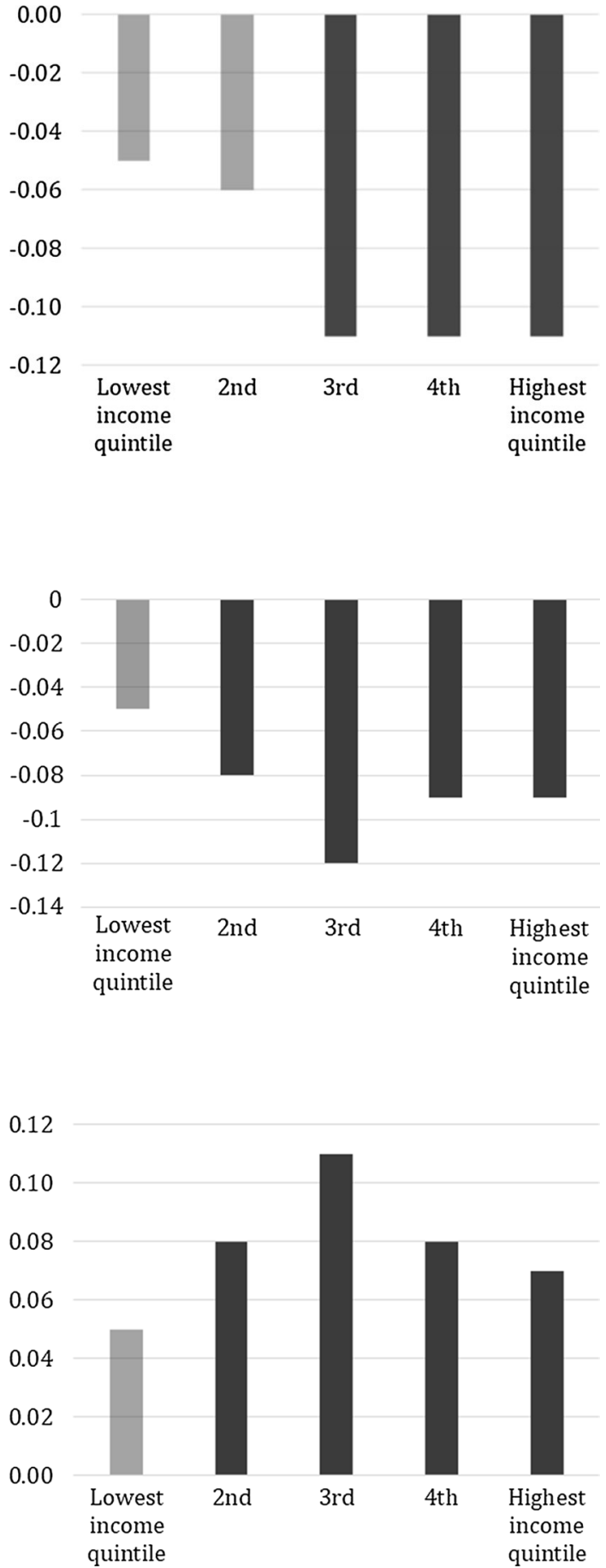
middle, upper middle and upper income group, it is weaker and not statistically relevant for the two lower income groups. This suggests than an egalitarian culture of strong self-expression values tones down inferiority feelings only for those with an average or better-than-average income position, but not for those down the income ladder - those which are most afflicted by inferiority feelings. Our second measure of an egalitarian culture, a trust culture, also yields dampening effects on inferiority feelings in all income groups. The well-being benefit of living in a trusting society is largest in the middle of the income distribution and levels somewhat towards both ends of the income distribution. Most importantly, towards the lower end (in the lowest quintile), this benefit is not statistically significant, in line with our findings for selfexpression values.

Finally, a climate of individual blame for poverty basically produces the same, yet inverted, pattern-here, all effects are positive, which signifies that inferiority feelings are increased across all income groups in cultures that stress individual blame (Fig. 4). Like for trust, the contextual impact is strongest for the middle income quintile and gets weaker towards both ends of the income distribution. Again, the increase of inferiority feelings is not statistically significant for the lowest income quintile. Put differently, a culture of individual blame for poverty puts a toll on the well-being of all income groups, except the poorest.

To summarize this step of our analysis, these findings contradict our hypothesis 3 , as we expected the impact of an (in)egalitarian culture to be felt at all rungs of the income ladder, and most strongly at the longest rung. Instead it appears that the poorest income quintile is rather insensitive to the societal cultural climate, whereas the middle income quintile is most sensitive.

\subsection{European Pattern or Cypriot Exceptionalism?}

Our analyses pointed towards the peculiar position of one country: Cyprus. Cypriots experience by far the highest level of inferiority feelings (see Fig. 1) and simultaneously show low levels of self-expression values and generalized trust as well as a high social norm to work and high levels of individual blame for poverty (see Fig. 2). We therefore repeated our analyses with a sample of 29 countries - excluding Cyprus. Re-estimating the full multilevel regression models of inferiority feelings on cultural and socio-economic country characteristics (the models 2-5 from Table 1) we find that coefficients become slightly smaller and all macro-level effects turn insignificant when considered simultaneously. When estimating the same models including only one country characteristic in turn (i.e. not controlling for GDP and income inequality in each model) we can replicate the above presented results: First, income inequality and a strong social norm to work do not exert an influence on inferiority feelings; second, higher GDP, as well as higher levels of self-expression values and a climate of trust, dampen inferiority feelings, whereas a culture of individual blame for poverty heightens them.

We also used these parsimonious models (i.e., without GDP and income inequality as country-level controls) to look into the differential effect of culture on the various income strata-again excluding Cyprus. We find a very similar pattern as for the full sample of 30 countries: a climate of self-expression values and trust exerts a negative (dampening) impact on inferiority feelings across all income quintiles, while a climate of individual blame for poverty exerts a positive (heightening) impact-however, like in the initial results presented above, these contextual effects are generally stronger and significant only in the middle and the two upper income strata. 


\section{Discussion}

Our study has departed from recognizing a growing interest of social scientists in inferiority feelings, both in their own right or as a key component of social well-being. The main concern is that inferiority is a catalyst of low individual and societal quality of life. Recent research on status concerns has come under criticism for its focus on income inequality as the concept of social hierarchy (Goldthorpe 2009) and the neglect of culture (Saunders and Evans 2010). Our paper attempts to address this criticism by focusing on climates of values and beliefs as cultural breeding conditions for status concerns, and to test their association with inferiority feelings using comparative cross-national data for 30 European countries. We hypothesized that egalitarian cultures dampen status concerns and that inegalitarian cultures fuel them, and that both effects are most relevant to the lower income ranks. Our results indeed suggest that culture plays a crucial role, fully supporting $\mathrm{H} 1$ and partially supporting $\mathrm{H} 2$; in contrast, our expectation regarding the sensitivity of lower income ranks for the prevalent culture was not born out, so that $\mathrm{H} 3$ is to be rejected. We want to highlight the following findings:

- From the four measures of culture we consider in our multi-level analyses, three prove significant for how much inferiority feelings Europeans experience: individual blame for poverty, social trust, and self-expression values. In contrast, a strong norm to work does not matter.

- As expected and in line with our theoretical argument, an egalitarian culture (trust, selfexpression) cushions inferiority feelings, whereas an inegalitarian culture (individual blame for poverty) heightens them.

- The contextual effects of culture work over and above the effects of national prosperity and the income distribution, which themselves are not significant contextual drivers of inferiority feelings in our set of 30 European countries. Excluding Cyprus (an influential case), the cultural characteristics as well as GDP, but not income inequality, shape inferiority feelings when considered as sole country characteristics.

- Not all income groups are (equally) sensitive to the cultural climate. In terms of inferiority feelings, the upper $80 \%$ of each population- $60 \%$ in the case of self-expression values - benefit from living in an egalitarian culture, and are harmed by an inegalitarian culture. The poorest $20 \%$, however, are largely unaffected by the cultural climate; their sense of inferiority is neither ameliorated, nor heightened by the surrounding culture. When excluding Cyprus, the poorest $40 \%$ are largely unaffected by the surrounding cultural climate.

These results put cultural forces that have been neglected up until now in the spotlight for understanding cross-national differences in status concerns in particular, and social wellbeing and societal quality of life more generally. Previous research has been mainly concerned with structural forces, especially the income distribution (Wilkinson 2005; Wilkinson and Pickett 2010; Layte 2012; Lindemann and Saar 2014; Paskov et al. 2017). Including culture in the examination of status concerns proves especially relevant as in our analyses culture turns out to be more important than the income distribution and economic 
prosperity. As Rosanvallon (2013) has argued, social equality-a state of society in which everybody is seen and treated as equal and thus receives social worth-does not necessarily flow from low distributive inequality in terms of income and wealth. Our results attest that these considerations are not unfounded, and that a more encompassing complementary change in values and beliefs is needed in order to make progress towards social equality and social well-being in contemporary societies.

At the same time, it would be to jump to conclusions to disregard the socio-economic context entirely, as a key question remains where an (in)egalitarian culture originates in the first place. In our data, a country's level of prosperity is strongly and positively associated with widespread self-expression values and trust, and negatively with individual blame for poverty; further, gaping income inequalities are associated with weak self-expression values and lower levels of trust (but hardly with stronger individual blame for poverty). These relationships are in line with previous studies (for self-expression values: Inglehart and Welzel 2005; for social trust: Delhey and Newton 2005; for poverty beliefs: Lepianka 2007; Lepianka et al. 2010). Although these are just correlations from which it is difficult to distinguish cause and effect, a prominent materialistic school of thought has provided convincing evidence that changes in socio-economic conditions precede changes in values and belief systems (Inglehart and Welzel 2005; Welzel 2013). This suggests that creating economic resources and distributing them more equally provide a good starting point for any policy attempt to induce a cultural shift towards more egalitarian and thus healthy values and beliefs. Generally, there are clearly more macro-level factors that have an impact on values and beliefs (Lepianka et al. 2010; Kallio and Niemelä 2013), and not all of them are capable of being influenced by public policy-e.g. religious traditions. Still, a non-materialistic starting point for culture change is the public discourse. To take the issue of poverty, official statements from governments and administrations could minimize references to individual blame and use a more sympathetic rhetoric instead, in the hope to change citizens' beliefs in the longer run.

Another noteworthy result is the differential effect of cultural climates across income groups as a more egalitarian culture appears to be better for many, but not for everyone Whereas a climate of trust and of self-expression values mitigates status concerns at least for the upper 60 percent, for the poorest income group(s) the positive effect of a strong selfexpression culture unexpectedly remains below the threshold of statistical significance. Our initial interpretation was that these cultures content-wise tap concerns that are least relevant for those at the bottom of the income hierarchy, e.g. lifestyle liberalization and gender equality in the case of self-expression values. However, this argument can hardly be made for a culture that blames poverty on individuals, which unexpectedly puts a toll on everyone's subjective social worth except those in the poorest income quintile(s). Seeing these patterns for all three measures of culture in conjunction, one is tempted to conclude that the poorer strata everywhere feel inferior first and foremost because they are low in the social pecking order. Culture cannot change this very fact, so that the poors' experiences of low worth hardly depend on the cultural context. This changes higher on the social ladder, where individual position in itself does not necessarily suggest a sense of low worth, so that the contextual culture plays out more strongly for the upper 60 percent, positively or negatively. Albeit, culture seems to produce more clear-cut effect differences 
across income groups than the income distribution does (cf. Layte and Whelan 2014; van Deurzen et al. 2015), which is also a genuinely new finding. We further find some evidence that the middle class is most sensitive to the cultural context, dovetailing with the idea of this group being very keen on maintaining and, if possible, improving its status (Schimank et al. 2014). This issue certainly deserve closer attention in future studies.

Our paper is one of a few demonstrating a contextual effect of culture on individual subjective wellbeing. So far, this has only been done for the social norm to work and life satisfaction (Eichhorn 2013; Stavrova et al. 2011; Stam et al. 2016). Thus we present a new area of application for self-expression values and poverty beliefs in particular. Future studies could explore how culture shapes other status concerns and wellbeing in general.

Our study is not without limitations. First, by applying multi-level models we were able to simultaneously account for individual and contextual factors, but due to data unavailability we could not control for all values and beliefs at the individual level. To address this issue, we used social trust as a proxy throughout, guided by the rich literature on trust and its concomitants, and all contextual effects we have reported include individual social trust. Still, we cannot entirely rule out that the cultural (contextual) effects of self-expression values and individual blame for poverty to some extent stem from individuals' value orientations and beliefs. Second, data availability and theoretical considerations reduced our sample to 30 countries, which is the lower limit of observations on the contextual level in multi-level analysis (Maas and Hox 2005). To mitigate this technical issue, items covering status concerns need to be included in surveys covering a wider range of (rich) countries. Third, as our data had a considerable amount of missing values, mostly for household income, that were not missing at random, we applied multiple imputation. The results from alternative model specifications including missings on income as a dummy variable and from our imputed models were very similar, which gives us great confidence in the robustness of our findings. Fourth, for reasons of space we only explored the effect of culture on the population overall, as well as on income quintiles. It is conceivable, though, that some manifestations of an (in)egalitarian culture-e.g. the social norm to work-impact only very specific subpopulations, e.g. the unemployed and those unable to work (cf. Stam et al. 2016).

Future research could thus look closer at such specific sub-groups and their sensitivity to macro-level conditions. Further, other value concepts such as power distance (Hofstede et al. 2010) or pertinent elements of the Schwartz value circumplex (Schwartz and Sagie 2000) can be employed to gauge (in)egalitarian cultures. Yet for our set of European societies and a multi-level strategy, country coverage was a crucial concern, which is why we gave preference to the four cultural measures used in the study at hand. As our research indicates, bringing culture in is a critical endeavor. An inegalitarian culture harms social well-being of large segments of the population whereas an egalitarian culture improves it, hence we should learn more about this relationship. Yet one crucial task remains: We need more research in order to better understand which contexts help to boost the self-esteem of those at the bottom rungs of the income ladder.

Open Access This article is distributed under the terms of the Creative Commons Attribution 4.0 International License (http://creativecommons.org/licenses/by/4.0/), which permits unrestricted use, distribution, and reproduction in any medium, provided you give appropriate credit to the original author(s) and the source, provide a link to the Creative Commons license, and indicate if changes were made. 


\section{Appendix}

Table 2 Inferiority feelings and macro-level variables based on EQLS data

\begin{tabular}{|c|c|c|c|c|}
\hline & $\mathrm{N}$ & Status anxiety ${ }^{a}$ & $\begin{array}{l}\text { GDP pc } \\
\text { PPP } / 1000^{b}\end{array}$ & $\begin{array}{l}\text { Income } \\
\text { inequality } \\
\text { (Gini) }^{c}\end{array}$ \\
\hline Austria & 1027 & $0.92(0.97)$ & 44 & 29 \\
\hline Belgium & 1009 & $1.33(0.86)$ & 41 & 25 \\
\hline Bulgaria & 975 & $1.52(0.99)$ & 15 & 35 \\
\hline Croatia & 995 & $1.43(0.94)$ & 21 & 30 \\
\hline Cyprus & 1001 & $1.85(1.11)$ & 30 & 30 \\
\hline Czech Republic & 1003 & $1.54(0.95)$ & 29 & 24 \\
\hline Denmark & 1020 & $0.58(0.83)$ & 43 & 25 \\
\hline Estonia & 996 & $1.33(0.79)$ & 24 & 33 \\
\hline Finland & 1012 & 1.07 (0.79) & 40 & 26 \\
\hline France & 2263 & $1.28(1.06)$ & 37 & 31 \\
\hline Germany & 3036 & $0.82(0.96)$ & 42 & 28 \\
\hline Greece & 989 & $1.53(0.96)$ & 27 & 33 \\
\hline Hungary & 1011 & $1.18(0.94)$ & 23 & 28 \\
\hline Iceland & 994 & $0.88(0.73)$ & 40 & 24 \\
\hline Ireland & 1051 & $1.32(0.80)$ & 45 & 29 \\
\hline Italy & 2244 & $1.30(0.91)$ & 36 & 33 \\
\hline Latvia & 992 & $1.41(0.91)$ & 20 & 35 \\
\hline Lithuania & 1116 & $1.46(0.85)$ & 22 & 35 \\
\hline Luxembourg & 991 & $1.25(1.01)$ & 91 & 27 \\
\hline Malta & 975 & $1.40(0.83)$ & 28 & 27 \\
\hline Netherlands & 1005 & $1.08(0.77)$ & 46 & 26 \\
\hline Poland & 2223 & $1.50(0.90)$ & 22 & 31 \\
\hline Portugal & 1008 & $1.19(0.91)$ & 27 & 34 \\
\hline Romania & 1510 & $1.59(1.01)$ & 17 & 32 \\
\hline Slovakia & 993 & $1.22(0.91)$ & 25 & 26 \\
\hline Slovenia & 998 & $1.16(0.87)$ & 28 & 25 \\
\hline Spain & 1510 & $1.05(0.89)$ & 33 & 34 \\
\hline Sweden & 1003 & $1.01(0.92)$ & 44 & 24 \\
\hline Turkey & 1984 & $1.28(0.97)$ & 18 & 38 \\
\hline UK & 2232 & $1.43(0.96)$ & 37 & 35 \\
\hline Total & 39,166 & $1.26(0.96)$ & 33 & 30 \\
\hline
\end{tabular}

${ }^{a}$ EQLS 2011-12. Weighted country means and standard deviation (in parentheses)

${ }^{\mathrm{b}}$ The World Bank, World Development Indicators 2016

'Solt 2016 
Table 3 Macro-level indicators of social values and social beliefs based on EVS data

\begin{tabular}{|c|c|c|c|c|}
\hline & $\begin{array}{l}\text { Self-expression } \\
\text { values }^{\text {a }}\end{array}$ & $\begin{array}{l}\% \text { Individual blame } \\
\text { (poverty) }^{\mathrm{a}}\end{array}$ & $\begin{array}{l}\text { Social norm to } \\
\text { work }^{\mathrm{a}}\end{array}$ & Generalized trust $\mathrm{t}^{\mathrm{b}}$ \\
\hline Austria & $58(21)$ & $28(45)$ & 68 (19) & $5.20(2.44)$ \\
\hline Belgium & $56(19)$ & $19(39)$ & $58(20)$ & $5.47(2.16)$ \\
\hline Bulgaria & 54 (19) & $25(44)$ & $76(16)$ & $4.52(2.41)$ \\
\hline Croatia & $52(20)$ & $22(41)$ & $60(18)$ & $4.59(2.5)$ \\
\hline Cyprus & 37 (19) & $44(50)$ & 75 (18) & $1.84(1.98)$ \\
\hline Czech & 59 (19) & $43(50)$ & $65(20)$ & $4.01(2.34)$ \\
\hline Denmark & 77 (17) & $14(35)$ & 63 (18) & $7.01(2.16)$ \\
\hline Estonia & $54(16)$ & $21(41)$ & 63 (19) & $4.79(2.44)$ \\
\hline Finland & 67 (18) & $20(40)$ & 57 (19) & $7.17(2.11)$ \\
\hline France & $62(19)$ & $16(37)$ & $61(21)$ & $5.32(2.01)$ \\
\hline Germany & 60 (19) & $23(42)$ & 68 (18) & $5.01(2.45)$ \\
\hline Greece & $50(22)$ & $30(46)$ & $69(18)$ & $4.28(2.31)$ \\
\hline Hungary & $58(18)$ & $33(47)$ & $72(17)$ & $4.33(2.39)$ \\
\hline Iceland & 75 (14) & $14(35)$ & 46 (17) & $6.33(2.38)$ \\
\hline Ireland & 53 (18) & $23(42)$ & $62(20)$ & $5.54(2.48)$ \\
\hline Italy & $45(21)$ & $23(42)$ & $69(17)$ & $4.83(2.12)$ \\
\hline Latvia & 57 (17) & $36(48)$ & $62(15)$ & $4.08(2.56)$ \\
\hline Lithuania & $60(16)$ & $21(41)$ & $63(15)$ & $4.54(2.54)$ \\
\hline Luxembourg & $61(20)$ & $22(42)$ & $67(22)$ & $5.92(1.91)$ \\
\hline Malta & $36(18)$ & $37(48)$ & 63 (16) & 4.65 (2.09) \\
\hline Netherlands & $63(22)$ & $19(40)$ & $53(18)$ & $6.23(2.00)$ \\
\hline Poland & $49(20)$ & $31(46)$ & $62(16)$ & $4.74(2.54)$ \\
\hline Portugal & $54(18)$ & $34(47)$ & $71(15)$ & $4.20(2.45)$ \\
\hline Romania & 49 (19) & 39 (49) & $71(17)$ & $4.95(2.57)$ \\
\hline Slovakia & $51(18)$ & $32(47)$ & 70 (18) & $4.13(2.10)$ \\
\hline Slovenia & $64(20)$ & $30(46)$ & $66(16)$ & $5.25(2.37)$ \\
\hline Spain & $63(21)$ & $24(43)$ & $64(17)$ & $5.41(2.33)$ \\
\hline Sweden & 77 (18) & $13(34)$ & $56(18)$ & $6.41(2.36)$ \\
\hline Turkey & 27 (17) & $29(45)$ & $81(16)$ & $4.88(2.55)$ \\
\hline UK & 57 (19) & $32(46)$ & 58 (19) & $5.50(2.51)$ \\
\hline Total & $55(22)$ & $27(44)$ & 66 (19) & $4.99(2.51)$ \\
\hline
\end{tabular}

Weighted country means and standard deviation (in parentheses). All values are unstandardized ${ }^{\mathrm{a}}$ EVS 2008, $\mathrm{N}=51,062,{ }^{\mathrm{b}} \mathrm{EQLS} 2011-12, \mathrm{~N}=37,440$ 


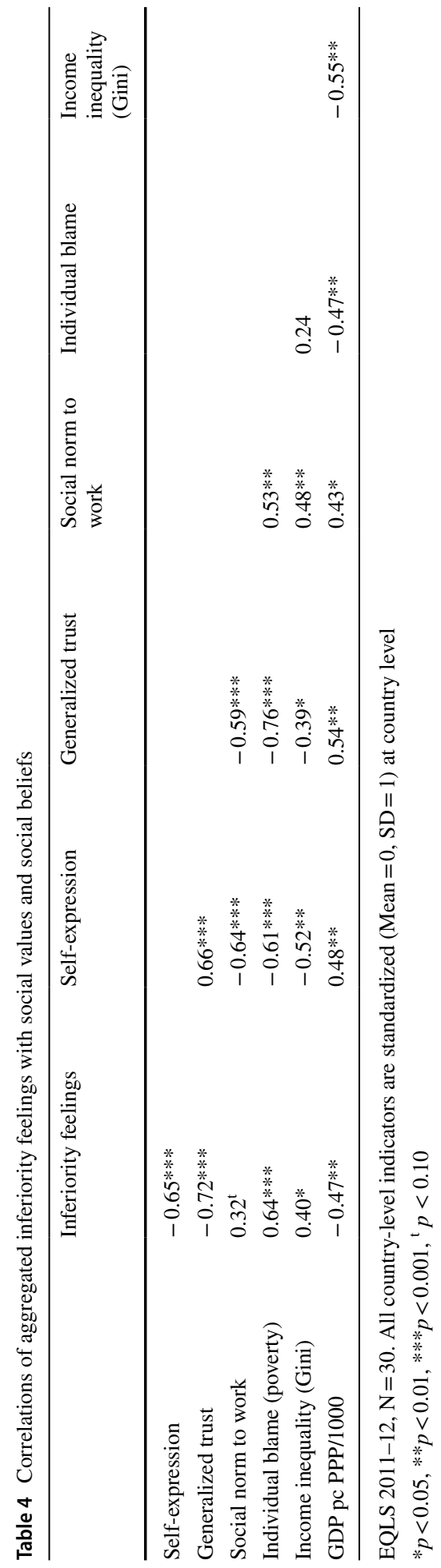




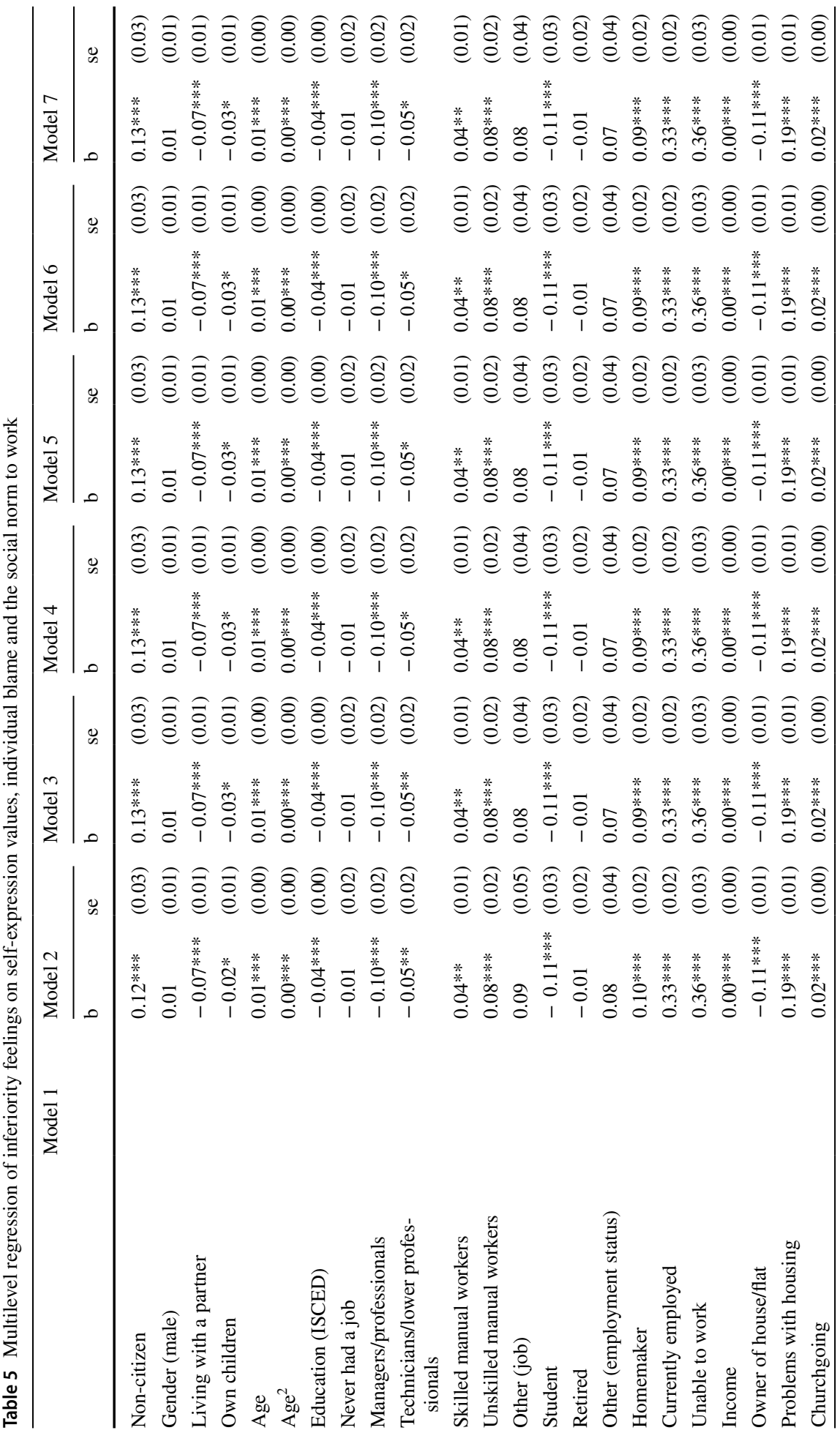




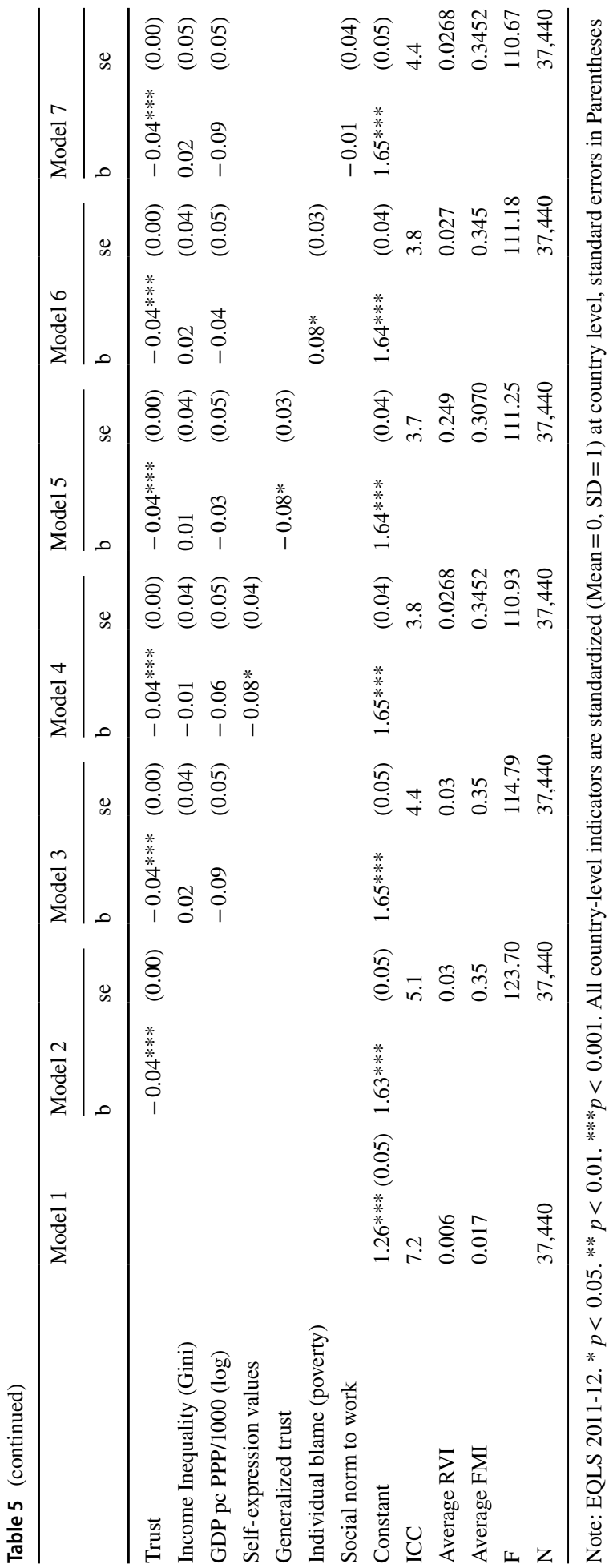




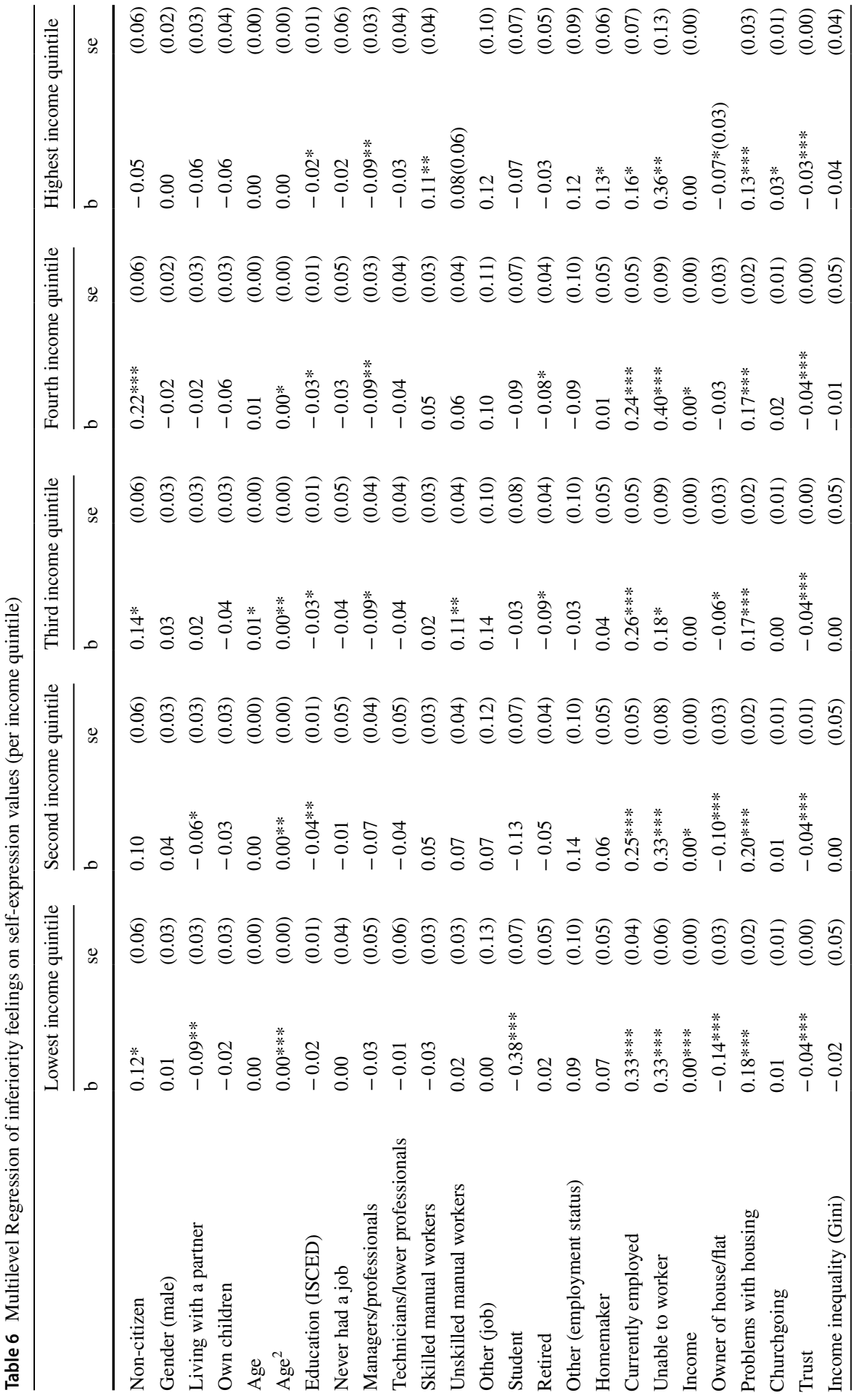




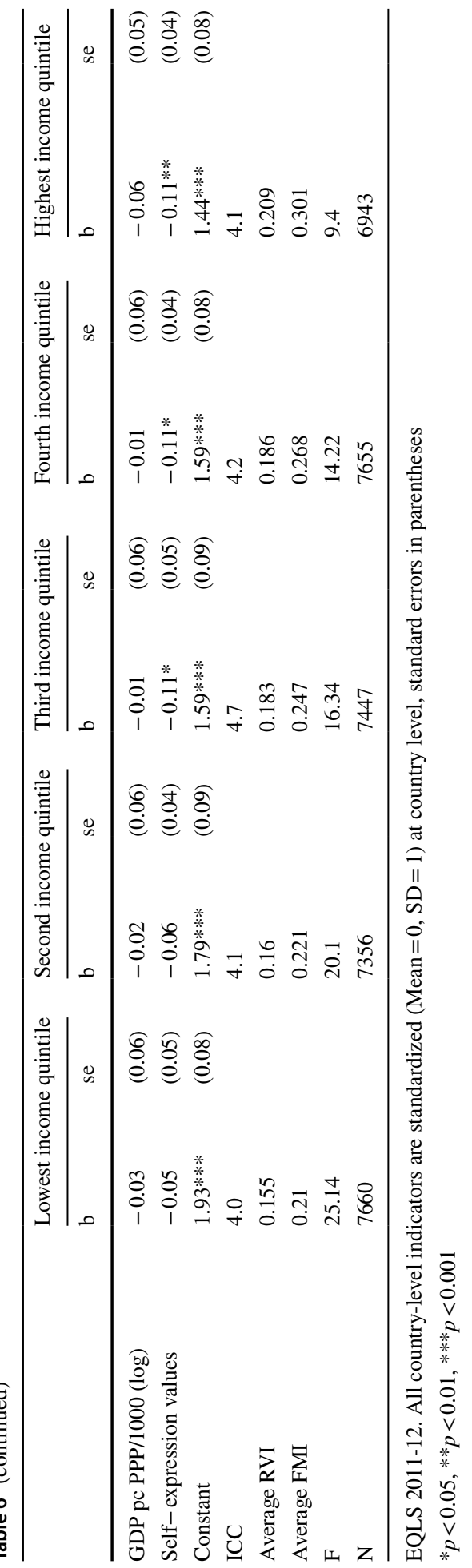




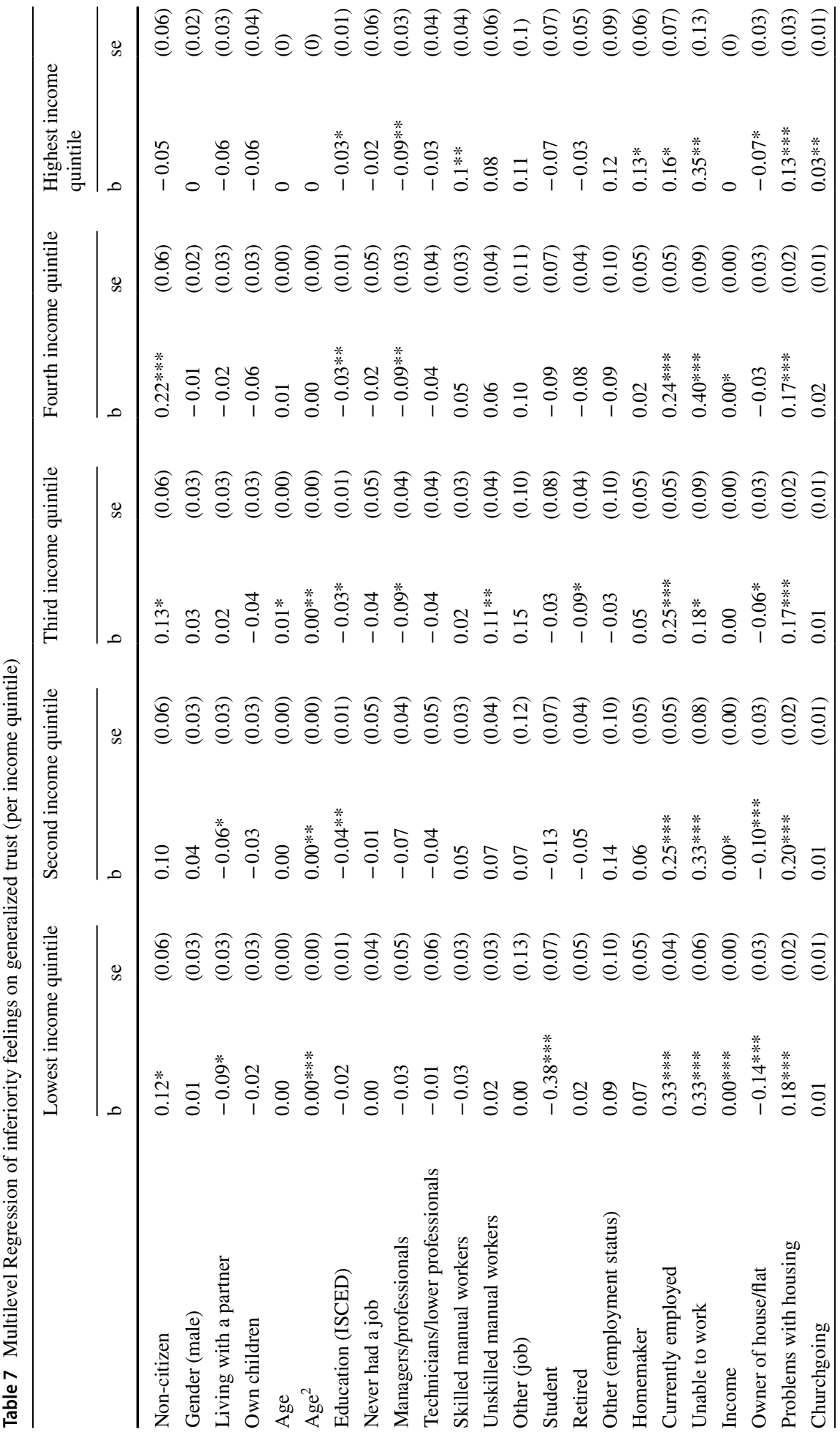




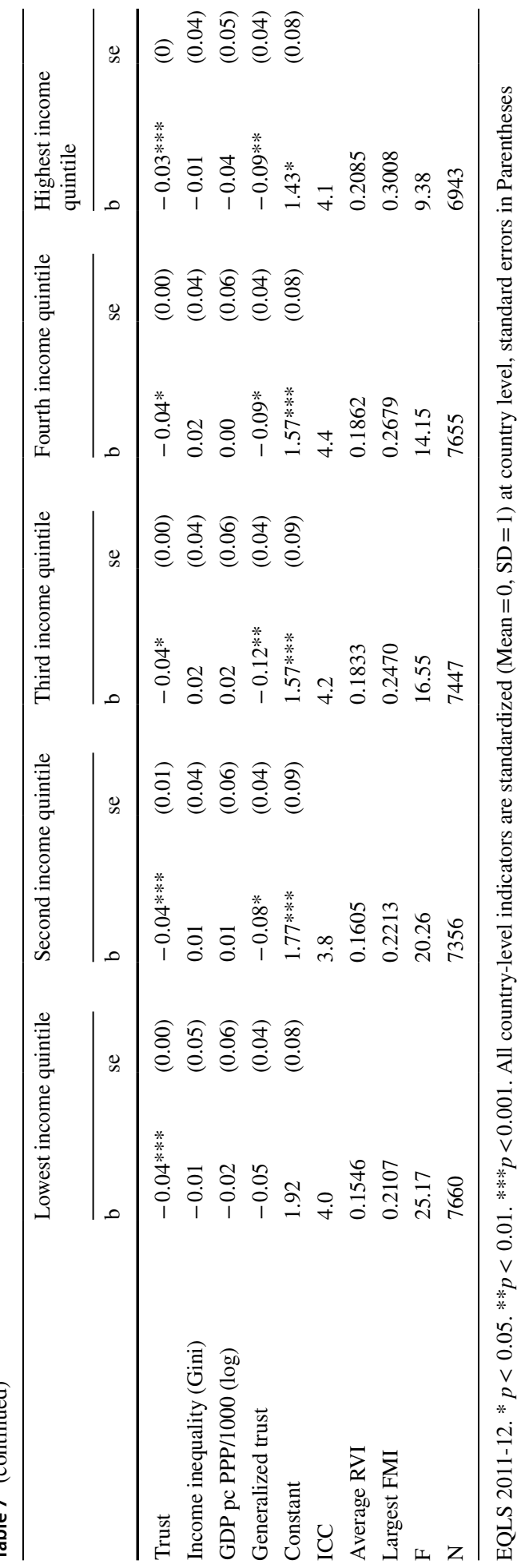




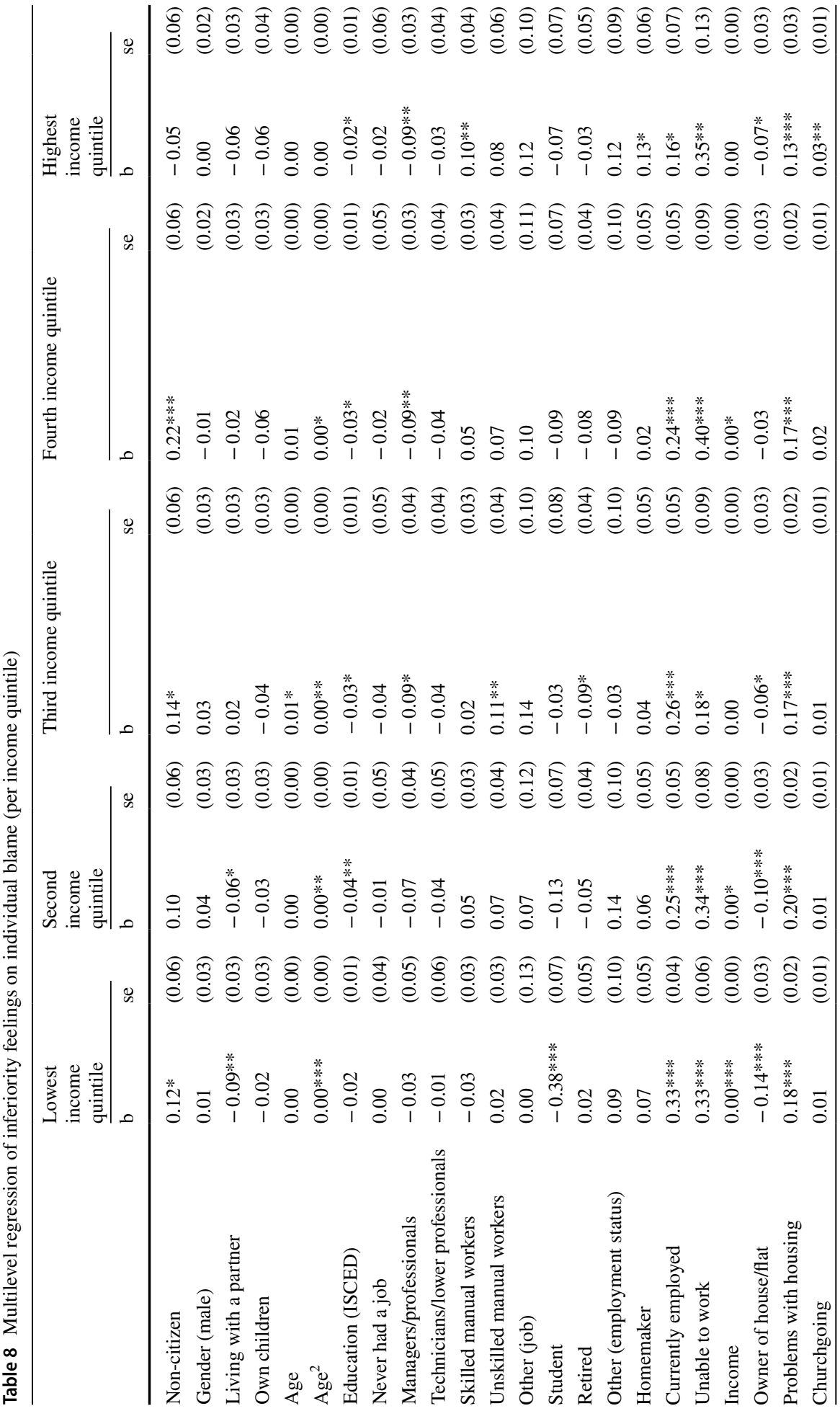









\section{References}

Böhnke, P. (2004). Perceptions of Social Integration and Exclusion in an Enlarged Europe. Luxembourg: Office for Official Publications for the European Communities.

Bjornskov, Christian. (2003). The happy few: Cross-country evidence on social capital and life satisfaction. Kyklos, 56(1), 3-16.

Bjornskov, C. (2008). Social trust and fractionalization: A possible reinterpretation. European Sociological Review, 24(3), 271-283.

Bobbio, A., Canova, L., \& Manganelli, A. M. (2010). Conservative ideology, economic conservatism, and causal attributions for poverty and wealth. Current Psychology, 29(3), 222-234.

Bourdieu, P. (1984). Distinction. A social critique of the judgement of taste. Cambridge, MA: Harvard University Press.

Bourdieu, P. (1998). Practical reason. On the theory of action. Cambridge: Polity Press.

Burkitt, I. (2014). Emotions and social relations. Los Angeles: Sage.

Calvo, Rocio, Zheng, Yuhui, Kumar, Santosh, Olgiati, Analia, \& Lisa, Berkman. (2012). Well-being and social capital on planet earth: Cross-national evidence from 142 countries. PLoS ONE, 7, e42793.

Delhey, J., \& Dragolov, G. (2014). Why inequality makes Europeans less happy: The role of status anxiety, distrust, and conflicts. European Sociological Review, 30(2), 151-165.

Delhey, J., \& Newton, K. (2005). Predicting cross-national levels of social trust: Global pattern or nordic exceptionalism? European Sociological Review, 21(4), 311-327.

Delhey, J., Schneickert, C., \& Steckermeier, L. C. (2017). Sociocultural inequalities and status anxiety: Redirecting the spirit level theory. International Journal of Comparative Sociology, 58(3), $215-240$.

Delhey, J., \& Steckermeier, L. C. (2016). The good life, affluence and self-reported happiness: Introducing the good life index and debunking two popular myths. World Development, 88(2016), 50-66.

Eichhorn, J. (2013). Unemployment needs context: How societal differences between countries moderate the loss in life-satisfaction for the unemployed. Journal of Happiness Studies, 14(6), 1657-1680.

Feagin, J. R. (1972). We still believe that god helps those who help themselves. Psychology Today, 6(6), 101-129.

Goldthorpe, J. (2009). Analysing social inequality: A critique of two recent contributions from economics and epidemiology. European Sociological Review, 26(6), 731-744.

Hofstede, G., Hofstede, G. J., \& Minkov, M. (2010). Cultures and organization. software of the mind. intercultural cooperation and it importance for survival. New York: McGraw Hill.

Honneth, A. (1995). The struggle for recognition. The moral grammar of social conflicts. Cambridge, MA: Polity Press.

Huppert, F. A., Marks, N., Clark, A. E., Siegrist, J., Stutzer, A., Vitters, J. V., et al. (2009). Measuring well-being across Europe: Description of the ESS well-being module and preliminary findings. Social Indicators Research, 91(3), 301-315.

Inglehart, R. (2008). Changing values among western publics from 1970 to 2006. West European Politics, 31(1-2), 130-146.

Inglehart, R., \& Oyserman, D. (2004). Individualism, autonomy, and self-expression. In H. Vinken, J. Soeters, \& P. Ester (Eds.), Comparing cultures: Dimensions of culture in a comparative perspective (pp. 74-96). Leiden: Brill.

Inglehart, R., \& Welzel, C. (2005). Modernization, cultural change and democracy the human development sequence. New York: Cambridge University Press.

Kallio, J., \& Niemelä, M. (2013). Who Blames the Poor? European Societies, 16(1), 112-135.

Lane, J.-E., \& Svante, E. (2002). Culture and politics. A comparative approach. Aldershot: Ashgate.

Layte, R. (2012). The association between income inequality and mental health: Testing status anxiety, social capital, and neo-materialist explanations. European Sociological Review, 28(4), 498-511.

Layte, R., \& Whelan, C. (2014). Who feels inferior? A test of the status anxiety hypothesis of social inequalities in health. European Sociological Review, 30(4), 525-535.

Lepianka, D. (2007). Are the poor to be blamed or pitied? A comparative study of popular poverty attributions in Europe. Tilburg: Tilburg University.

Lepianka, D., Gelissen, J., \& van Oorschot, W. (2010). Popular explanations of poverty in Europe. Effects of contextual and individual characteristics across 28 European countries. Acta Sociologica, $53(1), 53-72$.

Lindemann, K., \& Saar, E. (2014). Contextual effects on subjective social position: Evidence from European countries. International Journal of Comparative Sociology, 55(1), 3-23.

Little, R. J. A. (1988). Missing-data adjustments in large surveys. Journal of Business and Economic Statistics, 6(3), 287-296. 
Maas, C. J., \& Hox, J. J. (2005). Sufficient sample sizes for multilevel modeling. Methodology, 1(3), 86-92.

Miller, D. (1999). Principles of social justice. London/Cambridge: Harvard University Press.

Morris, T. P., White, I. R., \& Royston, P. (2014). Tuning multiple imputation by predictive mean matching and local residual draws. BMC Medical Research Methodology, 14(1), 1-13.

Newman, K. S., \& Ellis, C. (1999). "There's no shame in my game”: Status and stigma among Harlem's working poor. In M. Lamont (Ed.), The cultural territories of race: Black and white boundaries (pp. 151-181). Chicago: The University of Chicago Press.

Nolan, P., \& Lenski, G. (2004). Human societies. An introduction to macrosociology. Boulder: Paradigm Publishers.

Offer, A. (2006). The challenge of affluence. Self-control and well-being in the United States and Britain since 1950. Oxford: Oxford University Press.

Paskov, M., Gerxhani, K., \& Van de Werfthorst, H. G. (2017). Giving Up on the Joneses? The Relationship between income inequality and status-seeking, European Sociological Review, 33(1), 112-123.

Philips, D. (2006). Quality of life. Concept, policy and practice. London, New York: Routledge.

Präg, P., Mills, M., \& Wittek, R. P. M. (2016). Subjective socioeconomic status and health in crossnational comparison. Social Science and Medicine, 149(2016), 84-92.

Proto, E., \& Rustichini, A. (2013). A reassessment of the relationship between GDP and life satisfaction. PLOS ONE, 8(11), e79358.

Ridgeway, C. L. (2014). Why status matters for inequality. American Sociological Review, 79(1), 1-16.

Rokeach, M. (1973). The nature of human values. New York: Free Press.

Rosanvallon, P. (2013). The society of equals. Cambridge, MA: Harvard University Press.

Rosar, U. (2004). Ethnozentrismus und Immigration. In J. W. van Deth (Ed.), Deutschland in Europa. Ergebnisse des European Social Survey 2002-2003 (pp. 77-101). Wiesbaden: VS Verlag für Sozialwissenschaften.

Rothstein, B., \& Uslaner, E. M. (2005). All for all. Equality, corruption, and social trust. World Politics, $58(1), 41-72$.

Rubin, D. B. (1986). Statistical matching using file concatenation with adjusted weights and multiple imputations. Journal of Business and Economic Statistics, 4(1), 87-94.

Saunders, P., \& Evans, N. (2010). Beware false prophets. Equality, the good society and the spirit level. London: Policy Exchange.

Schimank, Uwe, Groh-Samberg, Olaf, \& Mau, Steffen. (2014). Statusarbeit unter Druck? Zur Lebensführung der Mittelschichten. Weinheim, Basel: Beltz-Verlag.

Schwartz, S. H., \& Sagie, G. (2000). Value consensus and importance: A cross-national study. Journal of Cross-Cultural Psychology, 31(4), 465-497.

Sennett, R. (2003). Respect in a world of inequality. New York: W.W. Norton.

Sennett, R., \& Cobb, J. (1972). The hidden injuries of class. New York: Alfred A. Knopf.

Singh-Manoux, A., Marmot, M. G., \& Adler, N. E. (2005). Does subjective social status predict health and change in health status better than objective status? Psychosomatic Medicine, 67(6), 855-861.

Skidelsky, R., \& Skidelsky, E. (2013). How much is enough? Money and the good life. London: Penguin Books.

Snowdon, C. (2010). The spirit level delusion: fact-checking the left's new theory of everything. Ripon, North Yorkshire: Little Dice.

Solt, F. (2016). The standardized world income inequality database. Social Science Quarterly, 97(5), 1267-1281.

Soroka, S., Johnston, R., \& Banting, K. (2007). Ethnicity, trust, and the welfare state. In R. Johnston \& F. Kay (Eds.), Social capital, diversity, and the welfare state (pp. 279-303). Vancouver/Toronto: UBC Press.

Stam, K., Sieben, I., Verbakel, E., \& de Graaf, P. M. (2016). Employment status and subjective well-being: The role of the social norm to work. Work, Employment \& Society, 30(2), 309-333.

Stavrova, O., Schlösser, T., \& Fetchenhauer, D. (2011). Are the unemployed equally unhappy all around the world? The role of the social norms to work and welfare state provision in 28 OECD countries. Journal of Economic Psychology, 32(1), 159-171.

Sztompka, P. (1999). Trust: A sociological theory. Cambridge: Cambridge University Press.

The World Bank, World Development Indicators (2016). GDP per capita, PPP (current international \$) [NY. GDP.PCAP.PP.CD].

Treiman, D. J. (1977). Occupational prestige in comparative perspective. New York, San Francisco, London: Academic Press.

Uslaner, E. M. (2002). The moral foundations of trust. Cambridge: Cambridge University Press. 
van Deurzen, I., van Ingen, E., \& van Oorschot, W. J. H. (2015). Income inequality and depression: The role of social comparisons and coping resources. European Sociological Review, 31(4), 477-489.

van Oorschot, W. (2005). Immigrants, Welfare and Deservingness: Opinions in European Welfare States. Aalborg University: Centre for Comparative Welfare Studies, Department of Economics, Politics and Public Administration.

Van Oorschot, W. (2006). Making the difference in social Europe: Deservingness perceptions among citizens of European welfare states. Journal of European social policy, 16(1), 23-42.

van Oorschot, W., \& Halman, L. (2000). Blame or fate, individual or social? An international comparison of popular explanations of poverty, European Societies, 2(1), 1-28.

Veblen, T. (1953 [1899]). The theory of the leisure class: An economic study of institutions, the mentor edition. New York: Macmillan.

Welzel, C. (2010). How selfish are self-expression values: A civicness test. Journal of Cross Cultural Psychology, 41(2), 152-174.

Welzel, C. (2013). Freedom rising. Human empowerment and the quest for emancipation. Cambridge: Cambridge University Press.

Welzel, C., \& Delhey, J. (2015). Generalizing trust: The benign force of emancipation. Journal of Cross Cultural Psychology, 46(7), 875-896.

Wilkinson, R. (2005). The impact of inequality: How to make sick societies healthier. New York: New Press.

Wilkinson, R., \& Pickett, K. (2010). The spirit level: Why more equal societies always do better. London: Penguin Books. 